\title{
An Awareness Survey on the Prevention of Covid-19 Infection at the Orthodontic Office
}

\author{
Anusha Sreedharan ${ }^{1}$, L. Xavier Dhayananth ${ }^{2}$, Shahul Hameed Faizee ${ }^{3}$, Navaneetha Nambi ${ }^{4}$, Evan A. Clement ${ }^{5}$ \\ 1,2,3,4,5 Department of Orthodontics and Dentofacial Orthopaedics, \\ Satyabama Dental College and Hospital, Chennai, Tamilnadu, India.
}

\section{ABSTRACT}

\section{BACKGROUND}

Covid-19 pandemic has created a havoc all over the world. In the view of orthodontists, the lockdown has brought financial, emotional, and professional restrain. In order to restart the practice, we need to have a sound knowledge on the guidelines issued by the authorities. We wanted to assess the knowledge of SARS CoV-2 infection, its impact on orthodontists and their understanding of the sanitation protocols in this study.

\section{METHODS}

500 orthodontic practitioners and postgraduates who reside in India participated in the study through an online questionnaire. Intergroup comparison was made among postgraduates (PG), private practitioners (PP), both in private practice and academic institutions (PA).

\section{RESULTS}

500 forms were completed and returned. The results were categorized into 3 sections - Knowledge on SARS-CoV-2, impact of Covid-19 on orthodontic practice and sanitation of the operatory. The study revealed the awareness of the infection among orthodontists at various levels of practice and their attentiveness in following Covid-19 protocol.

\section{CONCLUSIONS}

Orthodontic practitioners are very much aware of the seriousness of Covid-19 infection, method of spread, and its impact and sanitation protocols. Academic practitioners are more informed about the gravity of Covid-19 infection while private practitioners are robust in maintaining the sanitation standards of their operatories.

\section{KEY WORDS}

Orthodontist, Covid-19, Sanitation, Practitioner
Corresponding Author: Dr. Anusha Sreedharan, Dept. of Orthodontics and Dentofacial Orthopaedics, Sathyabama Dental College and Hospital, Chennai, Tamilnadu, India. E-mail: anusree1495@gmail.com

DOI: $10.14260 / j e m d s / 2021 / 500$

How to Cite This Article: Sreedharan A, Dhayananth LX, Faizee SH, et al. An awareness survey on the prevention of covid-19 infection at the orthodontic office. J Evolution Med Dent Sci 2021;10(31):2446-2450, $10.14260 /$ jemds/2021/500 DOI:

Submission 11-05-2021,

Peer Review 02-07-2021,

Acceptance 11-07-2021,

Published 02-08-2021.

Copyright (c) 2021 Anusha Sreedharan et al. This is an open access article distributed under Creative Commons Attribution License [Attribution 4.0 International (CC BY 4.0)] 


\section{BACKGROUND}

World Health Organization (WHO) reported a cluster of cases of pneumonia on 31 $1^{\text {st }}$ December 2019 in Wuhan, China and eventually by January, Coronavirus Disease-19 (Covid-19), also called as Severe Acute Respiratory Syndrome Corona Virus 2 (SARS - CoV - 2) was identified. By March 2020, there was a huge surge in the spread of infection that forced WHO to identify Covid-19 as a pandemic. ${ }^{1}$ An emergency leading to the suspension of various economic activities with only essential services like healthcare, government bodies involved in public services were spared. Covid-19 is caused by the SARS-CoV-2 virus that shares strong genetic similarity (>95\%) to known bat coronaviruses and later to those found in pangolins in China. ${ }^{2}$ It spreads among people, mainly when an infected person is in close contact with another person, when they cough, sneeze, speak or breathe heavily. These liquid particles are of different sizes, ranging from larger 'respiratory droplets' to smaller 'aerosols'. Other people may become infected by touching these contaminated surfaces, and then touching their eyes, nose, or mouth without having their hands cleaned. ${ }^{3}$ There are different ways by which Covid-19 can be present in saliva either directly from the lower and upper respiratory tract that enters the oral cavity, from the blood which can reach the mouth via crevicular fluid and salivary gland infection, or with subsequent release of particles in saliva via salivary ducts. ${ }^{4}$

Dental professionals are at a high risk of contracting Covid-19 infection, nevertheless orthodontic procedures come under the category of "Moderate urgent procedure" by the Ministry of Health and Family Welfare, Govt. of India. ${ }^{5}$ From the orthodontist point of view, not attending patients for longer time can have serious side effects like relapse, periodontal problems, and further increase in the duration of treatment. Hence, orthodontists are forced to get back to practice, keeping in mind the risk of infection through multiple transmission routes, from aerosols created during orthodontic procedures, treating patients who may have experienced indirect contact transmission, by removing and replacing aligners, appliances, and elastics. ${ }^{6}$ Orthodontists must be aware of the available evidence before restarting the practice.

The objective of the survey was to assess the knowledge and awareness among the orthodontists on safety measures for clinical examination and management of orthodontic patients. Extreme care for the patient and operator during Covid-19 pandemic is necessary during emergencies and also proper sterilization and sanitation of the orthodontic office to provide a safe environment for the society as a whole.

\section{METHODS}

The study was conducted in the Department of Orthodontics and Dentofacial Orthopedics, Sathyabama dental college, Chennai. The study protocol was approved by the Ethical Committee of Sathyabama Institute of Science \& Technology, Chennai, India. The study design constituted a questionnaire with closed ended and multiple-choice questions (other than demographic details). They were circulated among 500 orthodontic practitioners and postgraduates in India. The duration of the study was 6 months from September 2020 to March 2021.

The questions were framed according to the literature about infection control and other official guidelines. The questionnaire was categorized based on the demographic details (7 questions), knowledge on SARS-CoV-2 virus (4 questions), impact of Covid-19 on orthodontic practice (5 questions) and sanitation of the operatory (5 questions). The survey environment, allowed for anonymity, avoided the social desirability bias, thus induced the respondents to answer more honestly. Moreover, the questionnaire maintained the privacy and confidentiality of all information collected in the study. The participants were grouped into three categories: Postgraduates (PG), orthodontists involved in private practice \& academic institutions (PA) and private practitioners (PP). The face validity of the questionnaire was evaluated for the ease of understanding questions. Cronbach's alpha was used to measure the reliability and gave a score of 0.991 which indicated good reliability.

\section{Statistical Analysis}

Data were analyzed using the statistical software SPSS 21.0. A cross tabulation was used to understand the association between different variables and to detect patterns and trends within the data.

\section{RESULTS}

The demographic details of 500 respondents are given in Table 1.

\begin{tabular}{|c|c|c|c|}
\hline \multicolumn{2}{|r|}{ Profile } & Number & Percentage \\
\hline \multirow{2}{*}{ Gender } & Male & 247 & 49.3 \\
\hline & Female & 253 & 50.7 \\
\hline \multirow{5}{*}{ Zone of practice } & North India & 75 & 15 \\
\hline & East India & 19 & 3.8 \\
\hline & West India & 57 & 11.4 \\
\hline & South India & 328 & 65.7 \\
\hline & Central India & 21 & 4.2 \\
\hline \multirow{3}{*}{ Mode of practice } & Private practice & 178 & 35.7 \\
\hline & Postgraduates & 216 & 43.2 \\
\hline & Both in private practice $\&$ institution & 106 & 21.4 \\
\hline \multirow{4}{*}{$\begin{array}{l}\text { No. of patients } \\
\text { handled / day }\end{array}$} & $0-5$ & 308 & 61.6 \\
\hline & $06-10$ & 147 & 29.3 \\
\hline & $11-20$ & 27 & 5.4 \\
\hline & $>20$ & 18 & 3.6 \\
\hline \multicolumn{4}{|c|}{ Table 1. Sociodemographic Details } \\
\hline
\end{tabular}

Most of the orthodontists were aware that Covid-19 transmission could occur even through asymptomatic individuals. $76.2 \%$ of PA were aware of the asymptomatic contagious nature of this novel corona virus whereas $20.5 \%$ PP were not sure. Regarding the vitality of this virus in stainless steel and plastic, most of them believed that it lasts for three days whereas $31.8 \%$ of PG's believed that it lasts for 1 day. Most of them responded that presence of viral particles in aerosols were for three hours. Majority (75\%) of the orthodontists' supported that the treatment for a Covid-19 infected individual should only be after 2 negative test reports, while $11.5 \%$ of PP proceeded immediately with safety equipment.

$65.9 \%$ of PP preferred to attend walk in patients whereas $45.5 \%$ of the PG's allowed patients only with appointments. $68.7 \%$ of PP attended patients of all categories. $69.1 \%$ of 
PG's always used a consent form while $47.1 \%$ of PP used it occasionally. $59.6 \%$ of PP preferred to continue aerosol generating procedures with protective equipment and $30.8 \%$ PG's preferred to use hand instruments. Majority of the orthodontists were still uncertain of the effectiveness of virtual consultations.

\begin{tabular}{|c|c|c|c|c|c|}
\hline 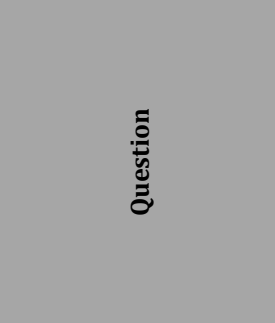 & 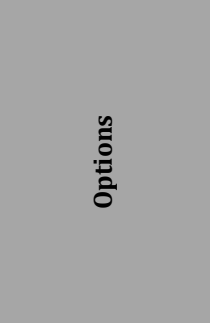 & 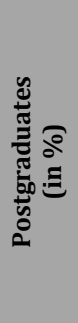 & 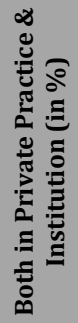 & 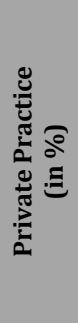 & 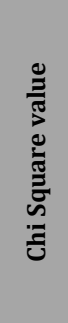 \\
\hline \multirow{3}{*}{$\begin{array}{l}\text { Does Covid-19 transmission } \\
\text { occur only through } \\
\text { symptomatic individuals? }\end{array}$} & Yes & 7.9 & 16.4 & 4.5 & \multirow{3}{*}{0.000} \\
\hline & Maybe & 20.5 & 16.9 & 19.3 & \\
\hline & No & 71.6 & 66.7 & 76.2 & \\
\hline \multirow{3}{*}{$\begin{array}{l}\text { How long do you think can } \\
\text { SARS-CoV-2 remain } \\
\text { infectious in stainless steel } \\
\text { and plastic? }\end{array}$} & 1 day & 31.8 & 27.3 & 20.5 & \multirow{3}{*}{0.000} \\
\hline & 3 days & 57 & 60.5 & 65.3 & \\
\hline & 5 days & 11.2 & 12.2 & 14.2 & \\
\hline \multirow{3}{*}{$\begin{array}{c}\text { How long do you think can } \\
\text { viral particles remain in } \\
\text { aerosols? }\end{array}$} & $0.5 \mathrm{hrs}$. & 15.5 & 18.8 & 15.9 & \multirow{3}{*}{0.000} \\
\hline & $3 \mathrm{hrs}$. & 54.6 & 57.7 & 62 & \\
\hline & $5 \mathrm{hrs}$ & 29.9 & 23.5 & 22.1 & \\
\hline \multirow{3}{*}{$\begin{array}{l}\text { When do you think it is safe } \\
\text { to treat a Covid-19 affected } \\
\text { individual? }\end{array}$} & $\begin{array}{l}\text { Immediately with } \\
\text { safety equipment's }\end{array}$ & 4.2 & 4.8 & 11.5 & \multirow{3}{*}{0.000} \\
\hline & $\begin{array}{c}\text { After } 14 \text { days of } \\
\text { positive report }\end{array}$ & 19.6 & 11.3 & 9.6 & \\
\hline & $\begin{array}{l}\text { After } 2 \text { negative test } \\
\text { reports }\end{array}$ & 76.2 & 83.9 & 78.9 & \\
\hline \multicolumn{6}{|c|}{ Table 2. Knowledge on SARS-CoV-2 } \\
\hline
\end{tabular}

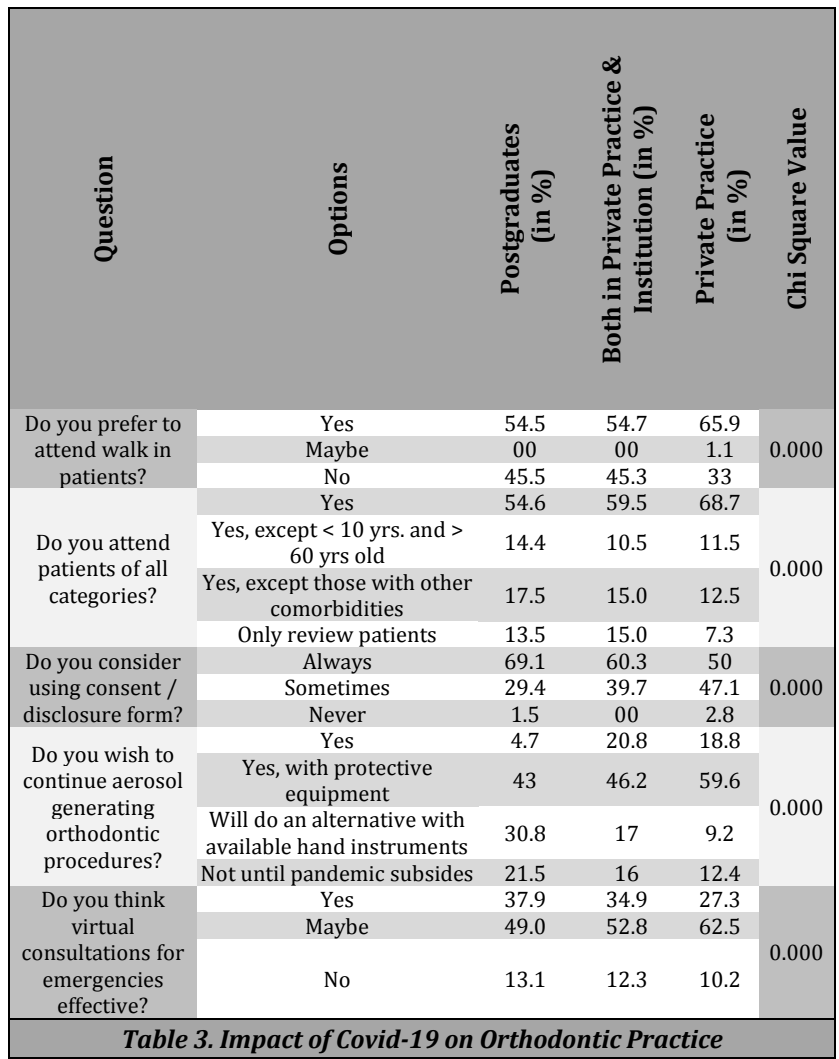

$46.4 \%$ of PP believed bonding a retainer to be an unavoidable aerosol generating procedure, where as $51.5 \%$ of PG's said bonding a loose bracket / buccal tube as an unavoidable aerosol generating procedure. $95.5 \%$ of PP disinfected the chair, spittoon, operator stool and tray area after every patient, while $13.6 \%$ of PG's disinfected the operatory at the end of each day. $80 \%$ of the respondents involved in P \& A preferred $1 \%$ Hydrogen peroxide or $0.2 \%$ povidone-iodine as the pre-procedural mouth rinse during the pandemic. $95.6 \%$ of PP were aware of the sequence of donning and doffing of PPE. Regarding the biochemical waste management protocol, more than $97 \%$ of orthodontists were aware of the same.

\begin{tabular}{|c|c|c|c|c|c|}
\hline 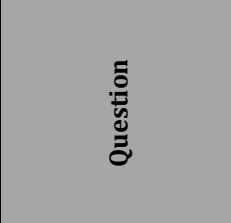 & 气̆ & 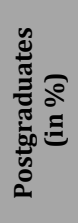 & 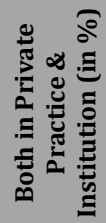 & 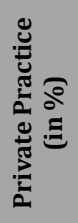 & 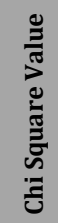 \\
\hline \multirow{3}{*}{$\begin{array}{l}\text { Which of these do you } \\
\text { consider an } \\
\text { unavoidable aerosol } \\
\text { generating procedure }\end{array}$} & $\begin{array}{c}\text { Bonding a loose bracket } \\
\text { / buccal tube }\end{array}$ & 51.5 & 42.5 & 31.6 & \multirow{3}{*}{0.000} \\
\hline & Bonding a retainer & 15.4 & 32 & 46.4 & \\
\hline & Oral prophylaxis & 33.1 & 25.5 & 22 & \\
\hline \multirow{3}{*}{$\begin{array}{c}\text { How often do you } \\
\text { disinfect chair, spittoon } \\
\text { operator stool \& tray } \\
\text { area? }\end{array}$} & After every patient & 82.7 & 90.6 & 95.5 & \multirow{3}{*}{0.000} \\
\hline & After 3 - 5 patients & 3.7 & 5.6 & 1.7 & \\
\hline & At the end of each day & 13.6 & 3.8 & 2.8 & \\
\hline \multirow{4}{*}{$\begin{array}{l}\text { Which of these do you } \\
\text { consider as a pre- } \\
\text { procedural mouth rinse } \\
\text { during the pandemic? }\end{array}$} & $\begin{array}{l}1 \% \mathrm{H}_{2} \mathrm{O}_{2} / 0.2 \% \\
\text { Povidone iodine }\end{array}$ & 72.4 & 80 & 79.6 & \multirow{4}{*}{0.000} \\
\hline & $0.2 \%$ povidone iodine & 0.5 & 4 & 1.1 & \\
\hline & $0.2 \%$ sodium fluoride & 0.5 & 4.5 & 0 & \\
\hline & $\begin{array}{l}0.2 \% \text { chlorhexidine } \\
\text { gluconate }\end{array}$ & 26.6 & 13.5 & 19.3 & \\
\hline \multirow{2}{*}{$\begin{array}{l}\text { Are you aware of the } \\
\text { sequence of donning } \\
\text { and doffing of PPE?? }\end{array}$} & Yes & 81.8 & 92.5 & 94.4 & \multirow[b]{2}{*}{0.000} \\
\hline & No & 18.2 & 7.5 & 5.6 & \\
\hline \multirow{2}{*}{$\begin{array}{l}\text { Are you aware of the } \\
\text { biomedical waste } \\
\text { management protocol? }\end{array}$} & Yes & 98.2 & 97.1 & 98.3 & \multirow[b]{2}{*}{0.000} \\
\hline & No & 1.8 & 2.9 & 1.7 & \\
\hline \multicolumn{6}{|c|}{ Table 4. Sanitation of the Operatory } \\
\hline
\end{tabular}

\section{DISCUSSION}

Covid-19 infection spread has led to cessation of economic activities all over the world. As per data released by the Ministry of Statistics and Programme Implementation, the Indian economy contracted by $23.9 \%$ in the first quarter of $2020 .{ }^{7}$ According to the report by American Dental Association (ADA), of all the orthodontic clinics, $89 \%$ were open with more than $50 \%$ of their regular patient flow. ${ }^{8}$ So, we have done a survey to assess the knowledge of SARSCoV-2 spread, its impact on orthodontic practice, sanitation protocol and infection control of the operatory in the orthodontic office.

Regarding the knowledge on SARS-CoV-2, and on enquiring about the vitality of virus, most of the orthodontic practitioners believed that viral particles stayed in aerosols for about 3 hours, but about $18.8 \%$ of PA responded that its life in aerosols to be 0.5 hours. Similarly, majority of the orthodontists and postgraduates responded that the vitality of the virus in stainless steel and plastic to be 3 days but around $31.8 \%$ of PA believed it to be only 1 day. According to a study published by Doremalen et al. they demonstrated that SARS-CoV-2 remained viable in aerosols for about 3 hours, with a reduction in infectious titer from $10^{3.5}$ to $10 .^{2.7}$ TCID $_{50}$ per liter of air. SARS-CoV-2 was more stable on plastic and stainless steel and viable virus was detected up to 72 hours although the virus titer was greatly reduced. ${ }^{9}$ This raises an apprehension among the orthodontic community and more valid research is required to prove its longevity. At present, it is better to take required safety protocol considering the unavailability of proper evidence. 
On enquiring about their readiness to treat a Covid-19 affected individual, more than $75 \%$ of orthodontists and postgraduates preferred to do so after 2 negative test reports, whereas $11.5 \%$ of PP proceeded immediately with safety equipment. This is an area of serious concern as the infection can spread to the next patient and their families. In a question and answer session by American Association of Orthodontists (AAO), they believed that coronavirus remained contagious only for 14 days of time from the onset of infection. ${ }^{3}$ Also Centers for Disease Control and Prevention (CDC) guidelines said, that those who never developed symptoms, isolation and other precautions could be discontinued 10 days after the date of their first positive RT - PCR test for SARS-CoV-2 RNA, and only a limited number of persons with severe illness produced replication - competent virus beyond 10 days that may warrant extending duration of isolation and precautions for up to 20 days after symptom onset. 10

On asking their opinion on considering new patients, 65.9 $\%$ of the PP were willing to take in new patients while about $45.5 \%$ of PG's and $45.3 \%$ PA preferred to see only patients with appointments. Similarly, on enquiring if they were willing to attend patients of all categories, $68.7 \%$ of PP were willing whereas $17.5 \%$ of $\mathrm{PG}$ and $15 \%$ of $\mathrm{PA}$ avoided patients with other co-morbidities. These results show that there still exists an edginess among the PG and PA whereas majority of the PP are prompt in tending to patients of all degrees. This can be attributed to their effort to maintain a constant flow of patients since the relaxation of lockdown.

Regarding the consent form $69.1 \%$ of PG's preferred to use a consent form while $47.1 \%$ of PP were still uncertain. In a narrative by Merivale et al. consent form is said to act as a 'legal flak jacket' and effectively protects the dentist from litigation. ${ }^{11}$ With respect to the aerosol generating procedures in our study, $59.6 \%$ of PP were ready to do aerosol generating procedures with protective equipment, which is similar to a study by Izzeti et al. whereas $88.5 \%$ of dentists adopted measures to limit aerosol production. ${ }^{12} 30.8$ $\%$ of PG's preferred to do the same procedure with alternative hand instruments, akin the guidelines issued by the Canadian Association of Orthodontists where they advocate the use of hand instruments wherever possible to minimize the risk of aerosols. ${ }^{13}$ Our results showed that PG's were more hesitant compared to PP in doing aerosol generating procedures. $50 \%$ of orthodontists and postgraduates were unsure about the efficiency of virtual consultation although $37.9 \%$ of PG's and $34.9 \%$ of PA believed it to be effective as reported by CDC guidelines where they suggest the use of teledentistry before in-office appointments of every patient. $1037.9 \%$ of PG's believed virtual consultations to be effective whereas $62.5 \%$ of PP were unsure. Virtual consultation is a boon during this period of emergency even though its effectiveness needs to be studied further.

Around $51.5 \%$ of PG and $42.5 \%$ of PA thought bonding a loose bracket or buccal tube to be an unavoidable aerosol generating procedure, while $46.4 \%$ of PP believed bonding a retainer to be so. This shows that there are numerous aerosols generating procedures associated with orthodontic treatment for which safety precautions are mandatory. One method to reduce the aerosols are the preprocedural mouth rinse. The CDC guidelines for dental settings advocate the use of preprocedural mouth rinses with an antimicrobial compound. ${ }^{10}$ According to the results of our study, $80 \%$ of PA considered $1 \% \mathrm{H}_{2} \mathrm{O}_{2} / 0.2 \%$ povidone iodine to be mouth rinse of choice during the pandemic while $26.6 \%$ of PG preferred $0.2 \%$ chlorhexidine mouth rinse. The IDA protocol advocates the patients to rinse the mouth with $1 \%$ hydrogen peroxide or $0.2 \%$ povidone iodine mouthwash for 1 minute. ${ }^{14}$ Even though there is no evidence to suggest the ideal mouth rinse, povidone iodine and chlorhexidine is known to reduce the viral load in many cases. ${ }^{15,3}$ Saki et al. have reported that both $0.2 \%$ povidone iodine or $1.0 \%$ to 1.5 $\%$ hydrogen peroxide have been recommended for patients due to the vulnerability of Covid-19 to oxidation. But its effect on orthodontic bonding procedures and orthodontic appliance susceptibility to corrosion and metal ion release is important and must be studied in detail. ${ }^{16}$

With respect to the disinfection of chair, stool, spittoon and operatory, it is mandatory to disinfect the operatory after each patient which is religiously followed by most of the PP (95.5\%). Nearly $13.6 \%$ of PG's prefer to sanitize at the end of each day, which raises an alarm and showcases the need to effectively impose sanitization after every patient into practice systematically.

On enquiring about the knowledge on the sequence of donning and doffing of personal protective equipment, majority of the practitioners were familiar whereas $18.2 \%$ of the PG's needed adequate training on the usage of PPE. The need for right technique should also be emphasized to the practitioners. More than $97 \%$ of PG, PP, PA were aware of the biomedical waste protocol, which is a favorable response.

On asking the right time to treat an infected individual, most of them preferred to see after 2 consecutive negative results. AAO briefs that a time gap of 14 days is sufficient from the $1^{\text {st }}$ positive test before any orthodontic treatment is begun. In a study by Kamate et al. $95.9 \%$ of dentists believed Covid-19 was fatal in nature, this fear and anxiety could be a reason for getting 2 negative reports. ${ }^{17}$ China, which is the first country to have overcome this Covid-19, stated that about two-thirds of the orthodontists (64.1\%) were willing to treat or care for patients with confirmed or suspected Covid-19, which uplifts our hope of a full-fledged practice in a safer environment. 18

\section{CONCLUSIONS}

The scientific literature on the SARS-CoV-2 is changing as new studies are progressing and discoveries are emerging on a day today basis. Previous studies have reviewed the risks of Covid-19, how it is perceived by dentists of various countries, including India. They have mostly categorized based on age, gender and showed that there are no significant differences within the groups. They have concluded that dentists are aware of the current scenario and have taken adequate safety measures, although few deficiencies in the knowledge exists regarding some vital aspects of Covid-19.19,20,21

Our study overall tells that specialty orthodontic practitioners are very much aware of the seriousness of Covid-19 infection, method of spread, its impact and sanitation protocols.

Regarding the knowledge about the gravity of Covid-19 infection, all the three groups were immensely aware. Private 
practitioners take best effort in maintaining the sanitation standards of their operatories compared to other groups. This extra care helps them for an undisturbed practice. Practitioners in both academic institution and private clinics are more conscious of the effects and consequences of the infection. Postgraduates need to take extra care to always maintain a sanitized operatory. Adequate training and continuous reinforcement of these protocols are necessary for a safe environment. Institutions should monitor these at regular intervals. Utmost care at the orthodontic office is necessary to prevent the spread of infection from patient to clinician and patient to patient or to their families.

Data sharing statement provided by the authors is available with the full text of this article at jemds.com.

Financial or other competing interests: None.

Disclosure forms provided by the authors are available with the full text of this article at jemds.com.

\section{REFERENCES}

[1] Mackenzie JS, Smith DW. COVID-19: a novel zoonotic disease caused by a coronavirus from China: what we know and what we don't. Microbiol Aust 2020:MA20013.

[2] Lam TT, Jia N, Zhang YW, et al. Identifying SARS-CoV-2related coronaviruses in Malayan pangolins. Nature 2020;583(7815):282-5.

[3] WHO. Coronavirus disease (COVID-19): how is it transmitted? World Health Organisation 2020.

[4] Gambarini E, Galli M, Di Nardo D, et al. A survey on perceived COVID-19 risk in dentistry and the possible use of rapid tests. J Contemp Dent Pract 2020;21(7):71822.

[5] Guidelines for Dental Professionals in Covid-19 pandemic situation. Ministry of Health and Family Welfare 2020:1-10.

[6] Sabino-Silva R, Jardim ACG, Siqueira WL. Coronavirus COVID-19 impacts to dentistry and potential salivary diagnosis. Clin Oral Investig 2020;24(4):1619-21.

[7] Kavaljit S. COVID-19 has pushed the Indian economy into a Tailspin. But there's a way out. The Wire 2020.

[8] ADA. COVID-19: economic impact on dental practices. Survey. American Dental Association 2020.
[9] Van Doremalen N, Bushmaker T. Aerosol and surface stability of SARS-CoV-2 as compared with SARS-CoV-1. N Engl J Med 2020;382(16):1564-7.

[10] Guidance for dental settings: interim infection prevention and control guidance for dental settings during the coronavirus disease 2019 (COVID-19) pandemic. Center for Disease Control and Prevention 2020.

[11] Merivale J. Adapting patient consent in response to COVID-19. BDJ In Pract 2020;33(8):26-7.

[12] Izzetti R, Nisi M, Gabriele M, et al. COVID-19 transmission in dental practice: brief review of preventive measures in Italy. J Dent Res 2020;99(9):1030-8.

[13] CAO. Returning to orthodontic practice during the COVID-19 pandemic. Canadian Association of Orthodontists 2020.

[14] IDA. COVID-19 Alert. Indian Dental Association 2020.

[15] Moosavi MS, Aminishakib P, Ansari M. 2020 Antiviral mouthwashes: possible benefit for COVID-19 with evidence-based approach. J Oral Microbiol 2020;12(1):1794363.

[16] Saki M, Najafi HZ. The COVID-19 pandemic suggests opportunities for researchers to investigate pertinent topics in orthodontics. Angle Orthod 2020;90(5):742-4.

[17] Kamate SK, Sharma S, Thakar S, et al. Assessing knowledge, attitudes and practices of dental practitioners regarding the COVID-19 pandemic: a multinational study. Dent Med Probl 2020;57(1):11-7.

[18] Hua F, Qin D, Yan J, et al. COVID-19 related experience, knowledge, attitude and behaviors among 2,669 orthodontists, orthodontic residents and nurses in china: a cross-sectional survey. Front Med 2020;7:481.

[19] Khader Y, Al Nsour M, Al-Batayneh OB, et al. Dentists' awareness, perception and attitude regarding COVID-19 and infection control: cross-sectional study among Jordanian dentists. JMIR Public Health Surveill 2020;6(2):e18798.

[20] Bansal P, Agnihotri A, Gupta A, et al. Emergency preparedness of oral health professionals during COVID19 pandemic: a knowledge, attitude and practices study. Indian J Dent Sci 2020;12(3):137-44.

[21] Chandra J. Knowledge, attitude and behavior of covid-19 among dental students at north India dental college-a questionnaire survey. European Journal of Biomedical and Pharmaceutical Sciences 2020;7(5):558-61. 